\title{
USO DE INDICADORES FINANCEIROS E NÃO FINANCEIROS PARA GERENCIAMENTO NAS ORGANIZAÇÓES: QUANDO DEVEM SER CONSIDERADOS KPI OU KRI
}

\author{
USING FINANCIAL AND NON-FINANCIAL INDICATORS FOR MANAGEMENT IN \\ ORGANIZATIONS: WHEN SHOULD BE CONSIDERED AS KPI OR KRI
}

\author{
Pedro Lucas Cruz \\ Universidade Federal de Santa Maria, Santa Maria, RS, Brasil, pedrolcruz2013@gmail.com
}

\section{Lucas Veiga Ávila}

Universidade Federal de Santa Maria, Santa Maria, RS, Brasil, lucas.avila@ufsm.br

Resumo: Este artigo tem como objetivo evidenciar como as organizaçôes podem usar indicadores financeiros e não financeiros por meio de KPI e KRI para o gerenciamento do resultado de suas atividades. Exemplos de indicadores utilizados no âmbito corporativo são apresentados, assim como, é realizada uma revisão da literatura, a fim de compreender a importância sobre o tema. Primeiro, explica-se a diferença entre indicadores financeiros e não financeiros. Em seguida, apresenta-se os conceitos de indicadoreschave e quando eles podem ser utilizados. Para abordar o tema indicador-chave de risco, realiza-se uma busca conceitual da importância do mapeamento e gerenciamento de riscos. Como principais resultados, pode-se salientar que a construção dos indicadores e escolha dos mais importantes, deve ser individual em cada empresa, a partir de suas necessidades e objetivos. No entanto, a revisão mostra que há um caminho que costuma ser trilhado para se obter sucesso no gerenciamento de resultados, desempenho e riscos.

Palavras-chave: Indicador-chave de desempenho. Indicador-chave de risco. Gerenciamento de riscos. Indicadores financeiros. Indicadores não financeiros.

\begin{abstract}
This article aims to highlight how organizations can use financial and non-financial indicators through KPI and KRI for the management of the result of their activities. Examples of indicators used in the corporate environment are presented, as well as, a literature review is carried out in order to understand the importance on the subject. First, the difference between financial and non-financial indicators is explained. Then, the concepts of key indicators and when they can be used are presented. To approach the key risk indicator theme, a conceptual search of the importance of risk mapping and management is carried out. As main results, it can be pointed out that the construction of indicators and the choice of the most important ones, must be individual in each company, based on their needs and objectives. However, the review shows that there is a path that is usually followed to obtain success in the management of results, performance and risks.
\end{abstract}

Keywords: Key risk indicator. Risk management. Financial indicators. Non-financial indicators. 


\section{Introdução}

Observando o cenário financeiro mundial nas últimas décadas, percebe-se que não mais existem empresas, em qualquer setor, que alcancem o sucesso organizacional sem que haja uma ampla disputa de mercado. Isso ocorre pelo aumento da busca por conhecimento, que permite às organizaçóes grandes avanços tecnológicos. A informação, ou o acesso garantido à ela, passa a ser um diferencial competitivo (Alvim, 1998). Ao mesmo tempo em que empresas sólidas do mercado são fortalecidas, novos espaços, produtos, tecnologias e oportunidades sáo gerados a cada minuto. Nesse sentido, devido à intensa competição, globalização e ao aumento exponencial da tecnologia, alguns fatores dominantes de vantagem competitiva são, justamente, a capacidade de inovação e a forma com que as informaçóes e as atividades como um todo são gerenciadas (Shahin \& Mahbod, 2007).

O gerenciamento em uma organização começa com a definição de seus principais indicadores, mesmo quando essa definição não é feita de maneira explícita. O gerenciamento através de métricas é algo intrínseco ao processo de empreender e surge quando há a necessidade de se resolver uma situaçáo problemática. Uma pequena parcela da população nasce com capacidades empreendedoras inatas ou intrínsecas, já outra parte precisa ser influenciada por fatores externos, como educação e cultura voltadas para a inovaçáo. Assim, entende-se que uma cultura empreendedora é fundamental e deve ser promovida na sociedade e, por consequência, dentro das organizaçóes, para impulsionar o crescimento do segundo grupo (Sarkar, 2014). O aumento de competitividade, comum em empresas, pode fazer com que percam participação no mercado e margem de lucro. Naturalmente, haverá uma busca por redução de custos, despesas e desperdícios, assim como por aumento de faturamento e de canais de venda. Percebe-se, entáo, que todas essas métricas estão no dia-a-dia de qualquer organização. $\mathrm{O}$ que não há, muitas vezes, é a estruturação e transformação dessas métricas em indicadores.

Um indicador constitui uma representação de forma simples - ou até intuitiva - de uma métrica passível de análises e comparaçóes, que permite uma gestão flexível, de acordo com as necessidades e objetivos de cada organização. É o que o próprio nome sugere: um indicador mede o progresso e o cumprimento de certas metas (Shahin \& Mahbod, 2007). Pode ser relativizado através de parâmetros ou fatores, elementos que auxiliam a comparação, transformando um indicador absoluto em relativo. $\mathrm{O}$ indicador absoluto costuma informar dados básicos, sem grandes análises ou interpretaçóes. Já o indicador relativo compara dados a partir do parâmetro definido e tende a ser mais ilustrativo (Kraemer, 2004). Exemplificando, pode-se acompanhar os gastos com energia elétrica em uma usina, fazendo comparaçóes históricas ou com referências externas; e pode-se acompanhar os gastos com energia elétrica por metro quadrado da usina. Nesse caso, o indicador de gastos com energia elétrica é considerado um indicador absoluto e gastos com energia elétrica por metro quadrado um indicador relativo.

Os indicadores geralmente fornecem informaçóes importantes sobre o sistema físico, social ou econômico da organização e permitem a análise de tendências e relações de causa e efeito (Veleva \& Ellenbecker, 2001). Existem duas categorias de indicadores: financeiros e não financeiros ou de desempenho. Aqueles que forem mais importantes para o resultado da organização podem ser considerados indicadoreschave. Esses, que devem ser revisados, normalmente, em ciclos - mensais, trimestrais, semestrais, anuais - servem para ilustrar o resultado e, quanto maior o intervalo entre suas revisôes, mais difícil se torna a mudança de direção e correção de desvios (Parmenter, 2015). A categorização de indicador financeiro 
e não financeiro facilita o processo de gestão e de tomadas de decisão em todos os níveis. Enquanto o primeiro serve para ser apresentado em nível estratégico, à direção e aos acionistas, o segundo tende a ser trabalhado internamente a nível tático e operacional, com a gerência, gestores, líderes de equipe e operadores responsáveis.

Este artigo tem como objetivo evidenciar como as organizações podem usar indicadores financeiros e não financeiros por meio de KPI e KRI para o gerenciamento do resultado de suas atividades. Na seção seguir são apresentados os principais conceitos e indicadores na revisão da literatura.

\section{Indicadores financeiros}

Os indicadores financeiros servem para mostrar, de forma abrangente, a situação econômica, financeira e patrimonial da organização (Silva, 2019), no que tange a liquidez e o giro dos ativos, o grau de endividamento e alavancagem de capital e as taxas de margem e retorno. Os dados essenciais para a construção dos indicadores e da análise do fluxo de caixa da empresa são obtidos, periodicamente, através das informações divulgadas na Demonstração do Resultado do Exercício (DRE) e no Balanço Patrimonial (Assaf Neto, 2020; Bruni, 2014).

Indicadores de liquidez servem para avaliar a capacidade monetária que uma organização tem para cumprir com suas obrigaçóes do Passivo, indicando a condição de sua própria continuidade (Martins, Miranda, \& Diniz, 2018). A Solvência de Caixa ou Liquidez Imediata, por exemplo, mostra a relação entre o caixa da empresa e o Passivo Circulante, ou seja, as obrigaçóes de curto prazo (Marion, 2012). A Liquidez Corrente compara o Ativo Circulante - bens e serviços que podem ser convertidos em caixa em curto prazo - com o Passivo Circulante. É o indicador financeiro de liquidez mais utilizado e mais amplamente divulgado entre as empresas. Isso porque ele relaciona os ativos que a empresa dispóe que possuem uma conversão em capital mais rápida, para poder sanar dívidas de curto prazo (Iudícibus, 2017). A Liquidez Seca realiza essa mesma comparação excluindo o Ativo de estoques, tornando-se interessante sua análise quando a empresa possui um baixo giro de estoques e, portanto, não pode contar com o dinheiro referente à venda dos produtos acabados em curto prazo (Silva, 2019). Por fim, a Liquidez Geral é a divisão de todos os ativos por todos os passivos. Nota-se que, quanto maior for o numerador, ou seja, os ativos da empresa, nesses indicadores, maior a possibilidade de geração de caixa, refletindo diretamente no capital disponível para arcar com os custos operacionais. Há de se destacar, também, a ideia equivocada de se igualar liquidez (ou capacidade monetária para saldar as dívidas) com capacidade de pagamento. Podem existir empresas com bons índices de liquidez que não estejam, obrigatoriamente, honrando com suas obrigações, em decorrência de outras variáveis (Matarazzo, 2010).

Indicadores de atividade, também conhecidos como índices de rotação, têm como objetivo mensurar as diversas etapas do ciclo operacional da organização e são obtidos pelo confronto dos elementos da DRE com os do Balanço Patrimonial. Utilizando o tempo como unidade de medida, esses indicadores visam evidenciar o prazo necessário para que os elementos do Ativo se renovem (Ribeiro, 2015). O Giro de Contas a Receber divide a receita pelas contas a receber. Para transformá-lo em Prazo Médio de Recebimento (PMR), multiplica-se o quociente por 365 dias. Quanto maior esse prazo, pior para a empresa, pois indica possíveis falhas estratégicas, seja com políticas de concessão de créditos, prazos muito estendidos para os clientes ou ineficiência do setor de cobrança (Silva, 2019). O Giro de Estoques divide 
o Custo da Mercadoria Vendida (CMV) pela posição do montante de estoque. Do mesmo modo, o Prazo Médio de Estoque (PME) é calculado multiplicando por 365 dias (Martins et al., 2018). Representa o índice de rotação de estoques: o período, em média, que a organização mantém seus produtos acabados. Quanto mais alta essa rotaçáo, menor o PME e melhor para a empresa, desde que isso seja reflexo de um aumento de demanda, de comercialização dos produtos e, consequentemente, de faturamento (Bruni, 2014; Silva, 2019). A somatória do PMR e PME resulta no Ciclo Operacional, que compreende as etapas operacionais desenvolvidas pela organizaçáo em seu processo produtivo. Quanto maior for essa somatória, maior o volume de recursos necessários para custear as atividades (Assaf Neto, 2020). O Giro de Contas a Pagar divide o mesmo CMV pelo total gasto com as compras e, utilizando o mesmo multiplicador de 365 dias em sua fórmula, obtém-se o Prazo Médio de Pagamento (PMP), que indica, em média, quantos dias a empresa leva para pagar os fornecedores (Ribeiro, 2015). Ao contrário dos anteriores, quanto maior for esse prazo, melhor para a empresa. A conjugação dos três prazos, ou a subtração do PMP no Ciclo Operacional, indicarão o Ciclo de Caixa ou Financeiro, que significa a quantidade de dias entre o pagamento feito aos fornecedores e o recebimento dos valores referentes à venda dos produtos adquiridos. Em outras palavras, quanto tempo a empresa detém o produto ou mesmo seus insumos, sem transformálo em capital (Assaf Neto, 2020; Marion, 2012; Martins et al., 2018). Por fim, a Necessidade de Capital de Giro (NCG) reflete a diferença entre os recebíveis e os compromissos. Enquanto o Ciclo de Caixa expressa o giro em dias, a NCG permite o cálculo do montante financeiro, ou quanto a empresa precisará de aporte de capital próprio ou de terceiros para manter sua operação (Marion, 2012).

Os indicadores de endividamento demonstram a relação entre as dívidas de uma empresa e o valor de seu patrimônio e ativos. O Índice de Participação do Capital de Terceiros (IPCT), por exemplo, representa o capital tomado emprestado de terceiros em relação ao capital próprio investido. Ao relacionar essas duas grandes fontes de recursos da empresa, torna-se possível analisar o risco ou a dependência de terceiros. Se o índice for maior que 100\%, significa que a empresa possui mais capital de terceiros do que capital próprio (Matarazzo, 2010). O Endividamento Financeiro é calculado a partir da divisão do total de dívidas pelo mesmo total de dívidas acrescido do patrimônio líquido. O Endividamento de Curto Prazo define-se pela relação entre dívidas a curto prazo e total de dívidas, enquanto o Endividamento de Longo Prazo tem como numerador as dívidas a longo prazo. O quociente dessas divisôes representa a relação das exigibilidades com os ativos. Assim, as dívidas de curto prazo são utilizadas, normalmente, para financiar o Ativo Circulante e as de longo prazo para financiar o Ativo Não Circulante (Azzolin, 2012). Outras maneiras de se medir o endividamento utilizam o cálculo do Índice de Cobertura de Juros, dividindo o EBITDA - Earnings before interest, taxes, depreciation and amortization - ou LAJIDA - Lucros Antes de Juros, Impostos, Depreciação e Amortização - pelo total de obrigaçôes de juros e a relação entre a Dívida Líquida e o mesmo EBITDA. Essa última mostra a necessidade de geraçáo de caixa da empresa para o pagamento de dívidas e indica, por exemplo, o grau de segurança perante uma crise financeira.

Outro indicador que envolve o capital de terceiros é o de alavancagem financeira. Serve para medir a proporção em que o total de ativos de uma empresa são financiados, ou seja, a capacidade que os recursos de terceiros utilizados, principalmente, para investimentos, apresentam para elevar seu lucro operacional (Assaf Neto, 2020). O GAF - Grau de Alavancagem Financeira - é calculado dividindo o lucro operacional pela diferença entre o lucro operacional e as despesas financeiras (Azzolin, 2012). Outro cálculo utilizado para considerar a alavancagem de uma empresa é o do MKP, ou Multiplicador de Capital 
Próprio, que divide o total de ativos pelo patrimônio líquido. Esse último representa o grau de cobertura dos ativos em termos dos recursos aportados pelos acionistas (Padoveze, 2017).

Os indicadores de margem ou rentabilidade, por sua vez, apresentam, geralmente em percentuais, a lucratividade de uma empresa aparece em linhas diferentes da DRE, de acordo com os tipos de custos e despesas consideradas em suas fórmulas. Os três mais conhecidos e usuais são a Margem Bruta, Margem EBITDA e Margem Líquida (Azzolin, 2012; Ribeiro, 2015). O primeiro reflete o lucro bruto da empresa em relação à receita líquida, ou seja, quanto do total das vendas sobra após a dedução dos custos diretos de compra e fabricação (Bruni, 2014). Nesse primeiro indicador, as despesas administrativas e de vendas não são levadas em consideração. A Margem EBITDA ou LAJIDA nada mais é do que o resultado operacional da empresa e equivale ao conceito de fluxo de caixa operacional, apurado antes do cálculo do imposto de renda. Consiste em um indicador do potencial de geração de caixa proveniente das operaçóes da empresa (Assaf Neto, 2020). Para avaliar se a empresa comercializa um produto operacionalmente viável, essa margem é suficiente. No entanto, não se pode avaliar, apenas com a Margem EBITDA, a rentabilidade da organização como um todo. Isso porque ela não considera as receitas e despesas não operacionais, tais como ganhos ou perdas na alienação de bens do ativo fixo e receitas e dívidas com instituiçóes financeiras (Matarazzo, 2010). Assim, é possível encontrar empresas que possuem margem operacional positiva, mas que, na linha final da DRE, não apresentam lucro. Por fim, o terceiro indicador a ser gerenciado é o de Margem Líquida, que leva em consideração os todos os custos e despesas. Demonstra, em uma linha geral, quantos reais a empresa ganha ou perde para cada real investido (Bruni, 2014) e tem muita importância, pois apenas quando seu resultado é positivo pode haver distribuição de lucro aos sócios e acionistas.

Os indicadores de retorno têm como objetivo demonstrar aos investidores que a empresa está gerando lucro suficiente para honrar os financiamentos. Os três mais importantes são conhecidos como ROA - Return on Assets ou Retorno sobre Ativos -, ROE - Return on Equity ou Retorno sobre Patrimônio - e ROIC ou ROI - Return on Invested Capital, Retorno sobre Investimento ou Retorno sobre Capital Investido -. O primeiro relaciona o lucro operacional com o total de ativos, indicando a eficiência com que a empresa usa os ativos para gerar vendas (Azzolin, 2012). O segundo, a relação entre o lucro líquido e o patrimônio líquido, expressando o retorno alcançado pelos acionistas a partir da gestáo dos recursos próprios e de terceiros realizada pela organização (Bruni, 2014; Martins et al., 2018). O terceiro divide o Lucro Líquido pelo Ativo Total, expressando, assim, a eficiência global da gestáo da empresa na geraçáo de lucros com o capital investido (Silva, 2019).

\section{Indicadores não financeiros}

Os indicadores não financeiros estão ligados à operação da empresa e diferem dos financeiros pelo fato de serem ilimitados. Tanto na academia quanto no âmbito organizacional, podem ser conhecidos como indicadores de desempenho, performance ou resultado. Isso porque medem, necessariamente, o desempenho de algum setor ou de alguma equipe, mostrando, através dos resultados, se a empresa está indo na direção e velocidade certas (Parmenter, 2015).

São inúmeras as possibilidades para gerenciar o resultado das áreas a partir de diversas dimensões que devem, necessariamente, estar relacionadas à estratégia da organização. Para garantir uma gestão eficiente, os indicadores devem ser tratados a nível tático e operacional e apresentados ao corpo diretivo, 
exibindo uma visão geral do progresso e alcance das metas (Parmenter, 2015). Pode-se mensurar, então, indicadores de produtividade, eficiência, qualidade, risco, inovação, sustentabilidade e outros tantos, conforme as perspectivas e objetivos do planejamento estratégico. A mensuração do desempenho pode ser definida como o processo de se quantificar uma ação (Neely, Gregory, \& Platts, 1995).

Exemplificando, pode-se citar os indicadores mais comuns dos principais setores de uma organização. No setor de Recursos Humanos, são comuns os índices de absenteísmo, turnover, Levantamento de Necessidade de Treinamento, horas extras e pesquisa de clima. No setor de suprimentos, pode-se avaliar o nível de atendimento em relação às solicitaçóes de compra, o custo evitado ou savings na compra de materiais diretos e indiretos. Para a área comercial, indicadores como Positivação de Clientes, Índice de Devolução, Nível de Serviço, Satisfação de Clientes e Taxa de Inovação tendem a ser muito importantes. No setor de produção também existem indicadores relevantes, como Eficiência de Equipamentos, também conhecida como OEE - Overall Equipment Effectiveness -, Peças por Hora, Índice de Geração de Refugo, Subproduto e Desperdício, Perda de Rendimento, Tempo entre Paradas de Máquinas e Consecução de Manutençóes Preventivas. Vale destacar que mesmo as empresas sem fins lucrativos devem possuir indicadores de resultado. Um hospital beneficente, por exemplo, pode medir a taxa de utilização e vacância de leitos, porcentagem de cobertura de serviços pelo sistema público de saúde, número de pessoas em tratamento, porcentagem de investimentos utilizados, volume de doaçóes e subsídios (Parmenter, 2015)

Nota-se que, apesar de serem chamados de indicadores não financeiros, eles estáo intimamente ligados ao resultado financeiro, pois ditam o resultado operacional que irá gerar o caixa para a empresa. Como estão identificados na cadeia de valor empresarial, devem preceder e auxiliar a mensuração dos indicadores financeiros (Neely et al., 1995). Analistas financeiros reconhecem a importância da informação não financeira para avaliação de empresas, pois ela indica as tendências de fracasso ou sucesso estratégico (Eccles \& Mavrinac, 1995). A título de exemplo, pode-se deduzir que, se um indicador não financeiro do setor comercial, como a Positivação de Clientes, estiver ruim, as vendas estarão abaixo do esperado e a empresa estará faturando menos. Com isso, a empresa necessitará realizar antecipaçóes ou vendas de ativos para continuar financiando sua operação e seus custos fixos, impactando negativamente o indicador financeiro de Liquidez Geral, pois há uma diminuição em seu numerador - os ativos - enquanto seu denominador - os passivos - continua o mesmo.

No que corresponde ao setor de produção, pode-se citar outro exemplo: o indicador não financeiro de Tempo entre Paradas de Máquinas, quando está desajustado, pode impactar no indicador financeiro de Ciclo de Caixa. Imagine que a empresa gerou obrigaçóes financeiras adquirindo insumos e, como a máquina teve muitas paradas para manutençóes corretivas, o produto teve um atraso em seu lead time de produção, que ocasionou atraso de entrega e, consequentemente, de recebimento. Durante todo esse acréscimo de tempo entre pagamento e recebimento, além dos insumos terem gerado custo de estoque, a empresa teve que aumentar a sua Necessidade de Capital de Giro para cobrir o aumento no ciclo. Citando um caso análogo, se o Índice de Geração de Refugo da empresa estiver muito alto, o lucro da operação estará também comprometido, à medida que cada porcentagem de refugo gerada diminui a porcentagem de margem operacional - ou margem EBITDA.

Por serem utilizados internamente como instrumentos de planejamento e controle estratégico, os indicadores não financeiros podem conter grandes diferenças de uma empresa para outra, podendo ser essencial em uma e na outra sequer ser mensurado. Além disso, esses indicadores tendem a se apresentar 
de forma limitada ao público, dada a sua extrema diversidade e ausência de padrão único para divulgação, como acontece com os indicadores financeiros (Dempsey et al., 1997).

Um erro comumente cometido por empresas que possuem sistemas de indicadores é a falta de conexão entre os mesmos, ignorando a necessidade de gestão holística dos indicadores. Para que isso seja evitado, eles devem ser definidos visando o resultado maior da empresa, como, por exemplo, o atingimento da visão. Dessa maneira, os indicadores estarão interconectados e direcionados a um único objetivo, não importando qual sua categorização (Badawy et al., 2016).

Entende-se, assim, que uma organização pode definir inúmeros indicadores ou métricas para gerenciar suas atividades, mas, por serem específicos para cada setor, nem todos serão considerados indicadores-chave da organização. Para tanto, devem ser selecionados os que mais impactam no resultado (Parmenter, 2015). Os indicadores-chave precisam ser estratégicos, para auxiliar a direção na tomada decisões, e se dividem em dois tipos: KPI e KRI.

\section{Indicador-chave de desempenho - KPI}

Indicador-chave de desempenho, também conhecido como KPI - Key Performance Indicator - é aquele que demonstra, em termos gerais, qual caminho a empresa está traçando de acordo com suas metas a níveis estratégico, tático e operacional (Parmenter, 2015). Em se tratando de vendas, por exemplo, a nível estratégico, pode-se definir como indicador o Faturamento Bruto; a nível tático, o Faturamento por Canal de Atendimento; e a nível operacional, o Número de Vendedores por Canal de Atendimento. Os três serão gerenciados de maneiras distintas, talvez por pessoas diferentes, mas estarão ligados a metas que possuem objetivo comum: geração de resultado.

É importante deixar clara a distinção entre metas e KPIs. A função do KPI é mensurar quanto da meta está sendo atingida e, para que seja bem definido, as metas também precisam ser bem definidas e traçadas no conceito SMART - Specific, Measurable, Attainable, Realistic, Time-sensitive -. As metas devem ser específicas e o mais detalhadas possível; devem ser mensuráveis, ainda que qualitativas; devem ser atingíveis, ainda que agressivas, para que não haja escusas por parte dos responsáveis e não se gaste recursos com algo inalcançável; devem ser realistas, dentro do cenário que se encontra a empresa; e, por fim, devem ter prazo para serem concluídas, possibilitando análise de seu progresso (Godoy \& Bessas, 2018; Parmenter, 2015; Shahin \& Mahbod, 2007).

O processo decisório para escolha de indicadores-chave de desempenho necessita ser feito com a participação de uma equipe de tomadores de decisão a níveis estratégico, tático e operacional, para que se encontre uma forma de selecionar aqueles indicadores que agregam às metas de cada área e, ao mesmo tempo, à meta geral da organização. Assim, espera-se que os interesses individuais sejam convergentes com os interesses da empresa. Nessa modalidade de grupo de consenso, os líderes participam de reunióes para definir quais indicadores se tornarão KPIs, através de uma ordem de etapas. O primeiro passo é listar todos os indicadores definidos pelos setores responsáveis. A partir disso, cada indicador listado deve ter explicitada a meta à qual ele está associado. Na segunda etapa, os indicadores que são importantes para o gerenciamento dentro dos setores, mas que não necessariamente impactam na meta global da organização, não devem ser tratados como indicadores-chave e podem ser desconsiderados. A terceira etapa é realizar 
uma comparação entre os indicadores que restaram e atribuir pesos para cada um, ou seja, a relevância que cada um pode ter em relação aos objetivos da empresa (Shahin \& Mahbod, 2007). Mesmo que a companhia decida incluir etapas no processo decisório, seguindo essa sequência lógica, ainda sim os KPIs mais relevantes serão selecionados de maneira objetiva e justa.

Suponha que uma empresa possua uma visão de ser o principal player no segmento de calçados em 5 anos. Assim, ela definiu, em seu planejamento estratégico, uma meta global de ter um acréscimo de $12 \%$ para $18 \%$ de market share no segmento de calçados esportivos em 12 meses. O responsável pelo setor industrial levou para a reuniáo diversos indicadores ligados a suas metas de área. No entanto, dois chamaram a atenção e receberam um peso maior: Índice de Geração de Subproduto e Peças por Hora. Entendeu-se que ambos estáo ligados à meta global, pois a redução na geração de subproduto e o aumento da produção de peças por hora fariam com que o setor comercial tivesse mais calçados de qualidade disponíveis para oferecer ao mercado. O gerente comercial levou seus indicadores e questionou ao grupo por que o seu indicador de savings na compra de materiais foi preterido em relaçáo ao de tempo de atendimento de compras. $\mathrm{O}$ grupo chegou à conclusão de que, embora o indicador de saving fosse importante para a consecução do orçamento comercial, o suprimento da demanda da produçáo, através do atendimento eficiente dos pedidos de compra, seria mais importante para o atingimento da meta global. O mesmo aconteceu com cada líder de equipe, até que se chegasse à definição dos KPIs da organização para aquele período. Assim, foram listados todos os indicadores e, após a conclusão das etapas, foram definidos os KPIs associados à meta global de aumento de market share, conforme a Tabela 1.

Tabela 1 - Lista de indicadores para definição de KPIs

\begin{tabular}{|c|c|c|c|}
\hline Indicador & Setor & Peso & Classificaçáo \\
\hline Satisfação de Clientes & Marketing & 1,00 & KPI \\
\hline Índice de aprovação final do produto & Qualidade & 1,00 & KPI \\
\hline Eficiência de máquinas e equipamentos & Industrial & 0,95 & KPI \\
\hline Taxa de inovação em produtos & $\mathrm{P} \& \mathrm{D}$ & 0,95 & KPI \\
\hline Positivação de Clientes & Comercial & 0,90 & KPI \\
\hline Peças por hora & Industrial & 0,90 & KPI \\
\hline Prazo de entregas de produtos & Logística & 0,90 & KPI \\
\hline Tempo médio de atendimento a solicitaçóes de materiais & Suprimentos & 0,85 & - \\
\hline Engajamento em redes sociais & Marketing & 0,80 & - \\
\hline Satisfação dos colaboradores & $\mathrm{RH}$ & 0,80 & - \\
\hline Turnover & $\mathrm{RH}$ & 0,80 & - \\
\hline Disponibilidade de ferramentas & Ferramentaria & 0,75 & - \\
\hline Geração de Refugo & Industrial & 0,75 & - \\
\hline Disponibilidade de máquinas & Manutenção & 0,75 & - \\
\hline Absenteísmo & $\mathrm{RH}$ & 0,70 & - \\
\hline Devolução por avarias logísticas & Logística & 0,60 & - \\
\hline Entrega das solicitaçôes de matéria prima & PCP & 0,60 & - \\
\hline Disponibilidade de sistema & T.I & 0,60 & - \\
\hline Horas extras & RH & 0,55 & - \\
\hline Margem de Contribuição por Produto & Comercial & 0,50 & - \\
\hline
\end{tabular}




$\begin{array}{lcr}\text { Realização das manutenções preventivas } & \text { Manutenção } & 0,50 \\ \text { Custo evitado na compra de materiais } & \text { Suprimentos } & 0,50 \\ \text { Prazo Médio de Pagamento } & \text { Suprimentos } & 0,45 \\ \text { Geração de Resíduos } & \text { Industrial } & 0,40 \\ \text { Levantamento de necessidade de treinamento } & \text { RH } & 0,40 \\ \text { Peso de despesas financeiras } & \text { Financeiro } & 0,30 \\ \text { Consecução do Orçamento Industrial } & \text { Industrial } & 0,30 \\ \text { Acurácia de Inventário } & \text { Contabilidade } & 0,10\end{array}$

Fonte: Elaborado pelos autores.

\section{Indicador-chave de risco - KRI}

Quando o indicador serve para identificar e monitorar qualquer exposição ao risco em relaçáo às metas globais da organização, ele deve ser tratado como indicador-chave de risco, ou KRI - Key Risk Indicator-, para que seu gerenciamento permita ações em tempo hábil, evitando possíveis crises no negócio. Um KRI pode ser financeiro ou não financeiro e fornece uma base confiável para estimar a probabilidade e a gravidade de um ou mais eventos de risco operacional. Pode ser estritamente quantitativo, como a taxa de rotatividade em uma determinada unidade, ou mais qualitativo, como adequaçáo a um novo sistema instalado. Pode ser mais objetivo, como número de horas de inatividade do sistema, ou mais subjetivo, como falta de atratividade no portfólio de produtos (Scandizzo, 2005).

O princípio do gerenciamento de riscos através da utilização de KRIs é agregar valor à organização. As atividades devem, então, ser projetadas para alcançar o melhor resultado possível e reduzir a incerteza dos resultados. A ISO 31000 inclui uma lista detalhada dos princípios sugeridos para gerenciamento de riscos, mas há de se destacar alguns, como: indicadores dinâmicos, iterativos e responsivos à mudanças; indicadores baseados em procedimentos e protocolos; gestáo alinhada com outras atividades do negócio; gestão abrangente, sistemática e estruturada; indicadores proporcionais ao nível de risco aceitável dentro da organização (Hopkin, 2017).

O nível de risco aceitável e que será utilizado ao definir os indicadores deve estar compatível ao chamado apetite ao risco do corpo diretivo da empresa. Também chamado de aptidáo, capacidade ou tolerância ao risco, pode ser definido como a quantidade de risco ao qual uma empresa está disposta a se expor e deverá ser o reflexo de sua capacidade de absorvê-los. Assim, se estabelece uma tolerância para a variaçáo dos lucros com base nos objetivos declarados pelos acionistas. Em se tratando de indicadores financeiros, por exemplo, a tolerância ao risco pode estar associada à variabilidade de ganhos, liquidez ou de diretrizes de aportes e investimentos (Chapman, 2012).

Dessa maneira, a implementação de programas de gerenciamento de risco conta com um entendimento dos tomadores de decisão da organização de que, quanto maior a exposição ao risco, mais eficaz deve ser a escolha dos indicadores a serem gerenciados. Essa escolha acontece a partir de um mapeamento de riscos. Embora esse termo seja muito utilizado, principalmente no setor bancário e de auditorias, não há um consenso de um mapa ideal, que se adeque a qualquer empresa, pois o mapeamento é um processo individual. No entanto, as três principais dimensôes de risco devem ser 
levadas em consideração. A primeira diz respeito aos processos, que em setores mais dinâmicos, podem mudar constantemente, tornando um mapeamento de riscos obsoleto da noite para o dia. A segunda dimensão é a de pessoas, que afetarão todos os processos da empresa à medida que interagem com eles, podendo haver diferentes níveis de interpretação e adaptação. Por último, deve-se respeitar o nível de especialização, que será a união das duas primeiras dimensôes. Quando essa interação atinge um nível satisfatório e, ocasionalmente, uma pessoa especializada se ausenta, o potencial para uma falha operacional aparece (Scandizzo, 2005).

Em comparação com outras ferramentas de gestão e medição de risco operacional, o gerenciamento dos KRIs, apesar de não ser um conceito novo para as empresas, ainda é ineficaz na maioria delas (Davies et al., 2006; Hopkin, 2017; Hubbard, 2009), deixando um mercado visivelmente suscetível a grandes crises, como as recessões de 2009 e 2020.

O conceito dos indicadores-chave de risco surgiu no mercado financeiro. Em 2005, para avaliar o apetite pelo risco de 38 grandes instituiçóes financeiras estadunidenses, a RMA - The Risk Management Association - realizou uma pesquisa a fim de entender como estavam seus programas de gerenciamento de risco e percebeu que a maioria deles ainda estava em estágio de planejamento. Outro objetivo da pesquisa foi garantir que as instituiçóes, após mapear perfis de alto risco em suas administraçóes, criassem ambientes seguros, com eficaz gerenciamento dos riscos. Três anos depois, uma crise financeira relacionada a hipotecas se iniciou e culminou no colapso no mercado imobiliário nos Estados Unidos (Davies et al., 2006). De acordo com o FMI - Fundo Monetário Internacional -, o colapso econômico e financeiro, em 2008, foi o segundo mais grave no país desde a Grande Depressão em 1930 (International Monetary Fund, 2020), sendo necessária a cessão de pacotes de resgate do sistema financeiro pelo governo norteamericano, para evitar a falência dos bancos.

A fim de exemplificar um KRI, pensemos que um indicador no setor comercial seja Número de Reclamaçôes de Clientes. Ele deve ser monitorado, pois expóe ao risco a quantidade de novas vendas e, consequentemente, o resultado da organização. Além disso, à medida que as reclamaçôes dos clientes crescem, aumenta a probabilidade de que erros potencialmente sistêmicos tenham começado a ocorrer dentro do próprio processo produtivo. Em outras palavras, existe uma razão para pensar que, pelo menos em alguns intervalos, as mudanças no valor desse indicador provavelmente estão associadas a mudanças em exposição ao risco operacional ou experiência de perda operacional (Davies et al., 2006).

Dessa maneira, percebe-se que há uma linha tênue que separa um KPI de um KRI, pois, dependendo do perfil dos tomadores de decisão, muitos indicadores de desempenho podem ser classificados como indicadores de risco. Nota-se que, nos exemplos supracitados, há uma distinção, no caso de vendas, entre o indicador de Satisfação de Clientes e o de Número de Reclamaçôes de Clientes. Apesar de ambos sugerirem o mesmo, devem ser gerenciados de maneiras distintas. $\mathrm{O}$ primeiro expóe a performance da equipe de vendas e do produto comercializado. Sendo assim, há maior preocupação em constância de resultado - manter a qualidade do produto, por exemplo. O segundo evidencia o risco ao nível de aceitação de novas vendas proporcionalmente à quantidade de novas reclamaçôes, ou seja, quanto maior for esse KRI, mais eficaz deve ser o plano de ação para melhoria do resultado, como a correção de defeitos de fabricação. 


\section{Considerações finais}

A revisão da literatura acerca dos exemplos de indicadores gerenciados pelas organizaçóes mostrou que, apesar de haver um consenso na importância dos indicadores financeiros e não financeiros mais usuais, o gerenciamento tende a ser particular para as empresas. Isso ocorre devido à necessidade de existir uma ligação entre os indicadores e os objetivos traçados pela companhia. Como o planejamento estratégico de cada empresa é diferente, pode haver heterogeneidade na escolha dos indicadores e, principalmente, dos indicadores-chave.

A partir da conceituação de indicadores financeiros e não financeiros, pode-se concluir que o segundo, muitas vezes, é denominado nas empresas como indicador de resultado, desempenho ou performance. Observou-se que, como os indicadores não financeiros precedem os resultados financeiros da organização, eles também são, de certa forma, indicadores financeiros. A principal diferença entre eles, de acordo com os autores, é que, enquanto os indicadores financeiros são limitados, os de desempenho podem ter inúmeras variaçóes, pois são escolhidos a partir da cadeia de valor, que varia de um mercado para o outro.

A escolha dos indicadores financeiros geralmente é definida pelos diretores e acionistas, que definem como querem avaliar a saúde financeira da empresa e acompanhar seus investimentos. Já os restantes dos indicadores são definidos pelos gerentes de área, que devem traçar as metas associadas ao planejamento estratégico junto ao corpo diretivo e executá-las junto à equipe responsável. Conclui-se, então, que o primeiro diz respeito ao nível estratégico da companhia, enquanto o segundo abrange os níveis tático e operacional.

Além disso, foram reforçados os conceitos de indicadores-chave de desempenho e de riscos, de acordo com o que traz a literatura. Pode-se concluir que os KPIs e os KRIs podem ser financeiros ou não financeiros, dependendo exclusivamente do grau de importância para o andamento das atividades e da exposição ao risco de não atingimento das metas globais, respectivamente. Ambos devem ser acompanhados pelo corpo diretivo regularmente, com o mínimo de intervalo de tempo possível, para que sejam passíveis de correçóes.

Gerenciar os KPIs significa, em termos gerais, acompanhar o progresso dos principais indicadores, que dirão se a empresa está no caminho e na velocidade desejados. O gerenciamento dos KRIs está ligado ao nível de risco que a empresa se considera capaz de absorver, podendo mudar de acordo com o cenário e momento que a empresa e os próprios acionistas estiverem atravessando.

\section{Referências}

Alvim, P. C. R. de C. (1998). O papel da informação no processo de capacitação tecnológica das micro e pequenas empresas. Ciência da Informação, 27(1), 28-35. https://doi.org/10.1590/S010019651998000100004

Assaf Neto, A. (2020). Estruturas e Análise de Balanços-Um Enfoque Econômico-financeiro (12a edição). São Paulo: Atlas. 
Azzolin, J. L. (2012). Análise das Demonstraçôes Contábeis. Curitiba: IESDE, Brasil.

Badawy, M., El-Aziz, A. A. A., Idress, A. M., Hefny, H., \& Hossam, S. (2016). A survey on exploring key performance indicators. Future Computing and Informatics Journal, 1(1-2), 47-52. https://doi. org/10.1016/j.fcij.2016.04.001

Bruni, A. L. (2014). A análise contábil e financeira ( $3^{\circ}$ ed). São Paulo: Atlas. https://www.travessa.com. br/a-analise-contabil-e-financeira-3-ed-2014/artigo/b3bda3cf-c864-4b67-9c4e-fbc1ba202bee

Chapman, R. J. (2012). Simple Tools and Techniques for Enterprise Risk Management: Chapman/Simple. John Wiley \& Sons, Ltd. https://doi.org/10.1002/9781118467206

Davies, J., Finlay, M., McLenaghen, T., \& Wilson, D. (2006). Key Risk Indicators - Their Role in Operational Risk Management and Measurement. 32.

Dempsey, S. J., Gatti, J. F., Grinnell, D. J., \& Cats-Baril, W. L. (1997). The Use of Strategic Performance Variables as Leading Indicators in Financial Analyst's Forecasts. SSRN Electronic Journal. https://doi.org/10.2139/ssrn.2346

Eccles, R. G., \& Mavrinac, S. C. (1995). Improving the corporate disclosure process. MIT Sloan Management Review, 36(4), 11.

Godoy, R., \& Bessas, C. (2018). Formação de Gestores. Criando as Bases da Gestão. Entenda Como Desenvolver Uma Gestão Focada em Resultados (1ª edição). Libretteria.

Hopkin, P. (2017). Fundamentals of risk management: Understanding, evaluating and implementing effective risk management (Fourth Edition). Kogan Page Ltd.

Hubbard, D. W. (2009). The failure of risk management: Why it's broken and how to fix it. Wiley.

International Monetary Fund. (2020). World Economic Outlook, April 2020. INTL MONETARY FUND.

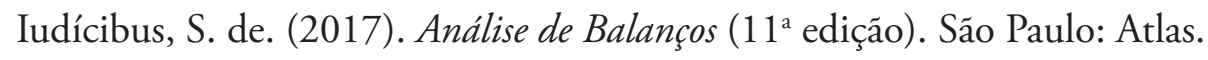

Kraemer, M. E. P. (2004). Indicadores ambientais como sistema de informação. Anais XXIV ENEGEP -Encontro Nac. de Eng. de Produção - Florianópolis, SC, Brasil, p. 5088-5095.

Marion, J. C. (2012). Análise Das Demonstraçôes Contábeis: Contabilidade Empresarial (7a edição). São Paulo: Atlas.

Martins, E., Miranda, G. J., \& Diniz, J. A. (2018). Análise Didática das Demonstraçôes Contábeis (2a edição). São Paulo: Atlas.

Matarazzo, dante C. (2010). Análise Financeira de Balanços: Abordagem Gerencial (7ª edição). São Paulo: Atlas. 
Neely, A., Gregory, M., \& Platts, K. (1995). Performance measurement system design: A literature review and research agenda. International Journal of Operations \& Production Management, 15(4), 80116. https://doi.org/10.1108/01443579510083622

Padoveze, C. L. (2017). Contabilidade Geral_Facilitada (1ª edição). São Paulo: Editora Método.

Parmenter, D. (2015). Key Performance Indicators: Developing, Implementing, and Using Winning KPIs (3rd edição). John Wiley \& Sons.

Ribeiro, O. M. (2015). Estrutura e Análise de Balanço Fácil (11 1 edição). São Paulo: Saraiva.

Sarkar, S. (2014). Empreendedorismo e Inovação (3 $3^{a}$ edição). Portugal: Escolar Editora.

Scandizzo, S. (2005). Risk Mapping and Key Risk Indicators in Operational Risk Management. Operational Risk Management, 26.

Shahin, A., \& Mahbod, M. A. (2007). Prioritization of key performance indicators: An integration of analytical hierarchy process and goal setting. International Journal of Productivity and Performance Management, 56(3), 226-240. https://doi.org/10.1108/17410400710731437

Silva, A. A. da. (2019). Estrutura, Análise e Interpretação das Demonstrações Contábeis (5ª edição). São Paulo: Atlas.

Veleva, V., \& Ellenbecker, M. (2001). Indicators of sustainable production: Framework and methodology. Journal of Cleaner Production, 9(6), 519-549. https://doi.org/10.1016/S09596526(01)00010-5 